\title{
Learning to Become a Taste Expert
}

\author{
KATHRYN A. LATOUR
}

JOHN A. DEIGHTON

Forthcoming, Journal of Consumer Research 
Kathryn A. LaTour is an Associate Professor of Services Marketing and Banfi Vintners Professor of Wine Education and Management in the SC Johnson College of Business at Cornell University. Kathy can be reached via email at kal276@,cornell.edu. John A. Deighton is the Harold M. Brierley Professor of Business Administration Emeritus at the Harvard Business School. John can be reached via email at: jdeighton@hbs.edu. Kathy dedicates this in memoriam to her husband Mike LaTour for his love, support and belief in this research investigation. The authors both would like to thank Tim Gaiser for his insights and introductions to the Master Sommeliers, and also the Institute of Master of Wine for allowing access to its advanced students.

Associate Editor: C. Page Moreau 


\begin{abstract}
Evidence suggests that consumers seek to become more expert about hedonic products to enhance their enjoyment of future consumption occasions. Current approaches to becoming expert center on cultivating an analytic mindset. In the present research the authors explore the benefit to enthusiasts of moving beyond analytics to cultivate a holistic style of processing. In the taste context the authors define holistic processing as non-verbal, imagery-based, and involving narrative processing. The authors conduct qualitative interviews with taste experts (Master Sommeliers) to operationalize the holistic approach to hedonic learning, and then test it against traditional analytic methods in a series of experiments across a range of hedonic products. The results suggest that hedonic learning follows a sequence of stages whose order matters, and that the holistic stage is facilitated by attending to experience as a narrative event and by employing visual imagery. The results of this multi-method investigation have implications for both managers and academics interested in how consumers learn to become expert in hedonic product categories.
\end{abstract}

Keywords: learning, expertise, holistic, analytic, sensory, hedonic 
Learning to be an expert takes time. The prevailing view in the consumer learning literature is that over time knowledge is acquired through experience, leading to more analytical, less holistic processing of new consumption objects. Alba and Hutchinson (1987 p. 420) say, "There is considerable evidence that experience increases analytical processing and decreases reliance on holistic processing." They conclude that analytic processing is associated with experts, while holistic processing is associated with novices (Alba and Hutchinson 1987). One way to become more analytical is to adopt a lexicon or a consumption vocabulary to decompose a stimulus. West, Brown and Hoch (1996) for example offered participants a vocabulary with which to describe attributes or features of stimuli and found that when consumers used it they were better at decomposing stimuli and reduced the probability of evaluation error, so that their preferences were more consistent than when they did not, they used more attribute information over time, and they were better able to self-report what was driving their preferences. In a word they behaved as if they were more expert.

Evidence suggests that consumers value the accrual of consumption knowledge as a means to enhance hedonic appreciation of future consumption (Clarkson, Janiszewski and Cinelli 2013). Artisanal sensory-driven products have sought to meet this consumer need by offering educational programs that teach consumers how to develop tasting skills. Demand for these programs has never been higher, with the wine industry leading the way (Drinks Business 2017), and other industries such as craft beer, coffee, tea, chocolate following. In general they have pursued analytic methods. The wine aroma wheel and the wine grid associate specific words with certain grapes to help consumers classify and describe their experiences (Noble et al. 1987). Embracing and using the lexicon is viewed as a critical component of the learning process and can lead to better memory for an otherwise ambiguous experience (LaTour and LaTour 2010; 
Maciel and Wallendorf 2017). We refer to the "analytics hypothesis" as the current view that expertise emerges from analysis of experience over sequential learning episodes.

In this paper we offer evidence to challenge the idea that expertise is simply a matter of more analytical processing and a more extensive vocabulary. Without disputing that as a consumer grows from novice to someone with middling competence (which we call an enthusiast) they may do more analytic processing and use a more technical vocabulary, we test the proposition that, in growing from enthusiast to expert, he or she should be trained to use a more holistic process and become independent from vocabulary.

The paper begins by presenting a theory of stages in skill acquisition that explains why initially analysis assists consumer learning to discriminate and assess ambiguous taste experiences, while also suggesting approaches that may be more effective in later stages of development. Experts experience fluency in their decision making which is a result of their ability to organize and bring their past knowledge to holistically assess a consumption object. In order to become more expert, we argue that those more intermediate will gain more from learning to assess holistically than analytically. Unfortunately there are contradictions in the way the term holistic processing is used by consumer researchers. We present what is known about holistic processing, propose a resolution of the contradiction, and develop hypotheses about hedonic learning. The empirical work begins with depth interviews with members of the Court of Master Sommeliers, a group of highly trained and extensively tested wine experts, on the subject of their own paths to, and attainment of, expertise. These interviews suggest a staged development process where sequencing matters, as well as insights into effective learning techniques. We follow this qualitative exploration with experiments involving the blind tasting of wine, coffee, chocolate and beer, to test the staged-learning theory. We contrast instruction to 
be analytic (telling consumers to use a grid made up of words that describe aspects of taste) and instruction intended to induce holistic thinking (telling them to use a shape-drawing task to depict taste). We discuss the implications of our findings for fostering imaginative thought and harnessing cross-sensory knowledge for consumer research focused generally on learning and expertise.

\section{CONCEPTUALIZATION}

Stages in Development of Expertise

What do experts have that novices do not? A dominant view in consumer research is that they have "more" of whatever novices lack and experts possess, be that decision criteria (Bettman and Sujan 1987), the ability to learn by analogy (Gregan-Paxton and John 1997) or a rich vocabulary (West, Brown and Hoch 1996). The most comprehensive review of expertise in a consumption context (Alba and Hutchinson 1987), implies that while "more familiarity" is the glib answer to the question, different tasks require different types of experience to produce familiarity, and so they conclude that the extensive psychological literature on task performance points to the need to distinguish five dimensions of expertise: more repetition; more refined, complete, and veridical cognitive structures; more ability to analyze information; more ability to elaborate on information; and more ability to remember.

But the fact that experts exhibit more of these dimensions of expertise than novices does not necessarily imply that they got to be expert simply by accumulating enough of the underlying 
experiences. By analogy with Piaget's proposal that human cognitive development from infancy to maturity proceeds in stages whose sequence matters (which we term stage-gated), learning to become an expert may be developmental, so that some experience is unproductive until other experiences have established a foundation.

There is a stream of work in psychology, not much applied in consumer research, which envisages just this kind of stepwise progress in learning a cognitive skill. Fitts (1964) proposed three steps for acquiring skills. The first phase is cognitive, in which the novice gains a general understanding of the task, stimuli, and cues. Only after significant progress in the first phase can it be followed by a phase in which successful cognitive processes are developed and inappropriate processes eliminated. Finally there is a phase where the task is performed with little or no conscious processing or effort.

In 1982 John R. Anderson wrote an influential theoretical paper, reassigning the work of Fitts's three processes into a simpler two-stage model. In the first stage, which he termed the declarative stage, facts about the skill domain are assembled. He wrote, "Verbal mediation is frequently observed because the facts have to be rehearsed in working memory to keep them available for the interpretive procedure." In the second stage, which he termed the procedural stage, production of skilled performance becomes fluent, refined by tuning but vulnerable to the Einstellung effect of Luchins (1942), a mechanized state of mind or problem-solving set that inhibits creativity. Anderson says experts can fluently move between perception and language (a condition he calls "tuning"). Melcher and Schooler (1996) find that taste experts show this ability, while those more intermediate have difficulty matching language to perceptual experience. 
Development of Hedonic Expertise is Stage-Gated

Consumer researchers studying taste learning have focused on the transition from the first stage of learning to the second, by finding ways to assist the consumer with language (LaTour and LaTour 2010). Rule-based grids and verbal lexicons have become part of the learning tools to teach mastery (Maciel and Wallendorf 2017 call this analytic approach "taste engineering”). "Taste engineering is a strategy of action to move towards connoisseurship, defined as the finegrained, discriminative faculty to judge and express taste according to the aesthetic principles of a consumption domain (Holt 1998; LaTour and LaTour 2010). Through the lens of practice theory, connoisseurship is the mastery of particular understandings, rules, and engagements implicated in a practice, a goal that requires both the cultivation of the sensorium and the use of a specific linguistic register (Lehrer 2009).”

Once the consumer has learned the rules and lexicon for analysis, over-reliance on them may lead to the Einstellung effect, impeding further development. Hedonic experiences like taste are generally not thought to be decomposable to a set of operations that lead to a definitive solution, so that more analysis is not necessarily a productive path forward (Wilson and Schooler 1991). In particular, consumers who evaluate their experience using words or a rule-book may emphasize non-distinguishing verbal information at the expense of critically applicable nonverbal information (Melcher and Schooler 1996). They attend to features that can be verbalized and overlook other important qualities so that they fail to appreciate the whole experience.

Gibson (1969) calls the whole sensory experience the holistic gist. In the same spirit, Klein (1998), in a study of naturalistic decision-making and expertise, posits that, in opposition 
to the traditional "analytics hypothesis," tools to develop expertise ought to focus on the holistic aspects of the experience.

For our purposes, the conclusion we take from this comparison of consumer research and psychological research is that there are two transitions on the path to acquiring hedonic expertise, the first involving the adoption of analytic methods and the second the abandonment of analytics in favor of attention to the holistic gist, and that the second transition can only occur after the first is achieved.

\section{HYPOTHESES}

We test this conceptualization with three hypotheses related to taste expertise, defined as a superior ability to discriminate between and recognize taste experiences (Hughson and Boakes 2001). We use recognition memory as the indicator of level of expertise. As a person becomes more expert, we take it as axiomatic that they will become better at recognizing which of an array of options they have earlier tasted.

The most general hypothesis (but to be clear not the first hypothesis we test) gets at the idea that recognition memory does not improve monotonically with analytical training, but that on the path to expert-like performance there is a discontinuity. Certainly novices move in the direction of expert levels if they are instructed to be more analytical. But enthusiasts, who are already competent analytically, do not benefit from further analytical instruction. They become more expert-like in response to holistic instruction.

H1: Novices (enthusiasts) will demonstrate better memory performance when encoding hedonic experiences analytically (holistically). 
What is Holistic Processing?

The term holistic processing is used in two quite contradictory ways in consumer research. Burroughs (1996), in his study of impulse buying, notes that "While consumers' use of holistic information processing strategies has been widely discussed in consumer research (cf. Alba and Hutchinson 1987; Cohen and Basu 1987; Holbrook and Moore 1981; Hutchinson and Alba 1991; MacInnis, Moorman and Jaworski 1991; MacInnis and Price 1987), it remains the more obscure of the two information processing styles."

One way the term is used is to describe the superficial processing of sensory information, without an effort to decompose the stimulus into attributes, and without first having acquired a vocabulary to support discrimination among attributes. This is how Burroughs (1996) uses the term in his work, and how Alba and Hutchinson (1987) use it to describe novice processing as distinct from expert processing. These authors use "holistic" and "non-analytic" interchangeably, such that holistic in their view involves a simplistic surface evaluation.

The other way is quite different, without any suggestion that holistic processing is more superficial than the style to which it is contrasted. Holbrook and Moore (1981) use 'holistic' in contrast to 'atomistic' or 'analytic.' In their terms it is right brained, gestalt-like and able to recognize numerous feature effects and interactions among elements. Adaval and Wyer (1998) use 'holistic' in contrast to 'piece-meal,' by which they mean attention to specific features. Both Monga and John (2007) and Bhargave and Montgomery (2013) follow Nisbett, Peng, Choi, and Norenzayan (2001) in saying that holistic thinking involves an orientation to the context or field as a whole, whereas analytic thinking involves a detachment of the object from its context and a 
focus on attributes of the object. Again there is no suggestion that holistic processing is a superficial mode of thought. The complexity and sophistication of holistic processing is also invoked to account for human skill at processing facial information. Richler, Palmeri and Gauthier (2012) note that holistic processing is the central concept used to explain why facial recognition relies more on attention to the whole face than features presented sequentially. However they caution that the term is used to describe a range of theoretical concepts and measured effects that may involve different mechanisms.

Anticipating this concern, we define holistic processing as a mode of thought in which consumers attend to and encode their experience as a whole, independent of vocabulary or attribute decomposition. We operationalize it as the joint operation of two more familiar processes: narrative processing (Adaval and Wyer 1998) and imagery coding (Holbrook and Moore 1981).

Developing Expertise with the Enthusiast

Researchers find where enthusiasts and experts differ most is not in their declarative/conceptual knowledge of a subject but rather their ability to bring their knowledge and skills together to perform (Geeves et al 2013).

In context of taste learning we suggest that the enthusiast needs a learning approach that allows them to organize their perceptual experience into a holistic gist. Researchers have considered time-paced narratives as such a structure (Adaval and Wyer 1998). Narratives can help set a framework for understanding: "Narratives and stories serve as blueprints for behavior and goal-attainment. As such, they organize moment-to-moment experiences that are required to 
establish and attain goals. In this way, narratives help us to anchor us in our bodies through time" (Cozolino 2002). Narratives can help consumers get close to experience. Deighton, Romer and McQueen (1989) found when ads followed a narrative form, participants were more drawn into the ad-watching experience than when the form was that of an argument. Following Green and Brock (2000), Wang and Calder (2006) used the term "transportation" to describe how, in narrative information processing, a person is absorbed into the flow of a narrative in a pleasurable and active way. Escalas (2007) found that narratives "transported" ad audiences into consumption experiences.

H2: A learning approach that encourages the enthusiast to encode their experience into a narrative structure will result in better memory performance than one that encourages a decompositional structure.

Holistic processing harnesses the power of imagery. An important aspect as the enthusiast learns to become more expert is developing tuning between conceptual and perceptual experience which involves removing the barrier of language. MacInnis and Price (1987) define imagery as a process of representing sensory structure in working memory. Imagery allows for parallel rather than sequential processing of attributes (Townsend and Kahn 2013) leading to more gestalt -like processing instead of the piecemeal processing associated with verbal stimuli. Spatial representations of these images exploit the perceptual-motor system. This may allow consumers to extend working memory capacity, so that they can capture important low level features and identify patterns useful for later memory tasks. Meanwhile verbal encoding impairs retrieval of the memory for perceptual attributes for enthusiasts through verbal overshadowing. If encoding can be achieved without relying on words, it follows that the retrieval impairment will 
not occur. And if the alternative encoding process achieves equal ability to encode perceptual information, retrieval will be enhanced.

H3: A learning approach where the enthusiast encodes the taste experience using images rather than words will lead to greater memory performance.

We use qualitative interviews with taste experts to build on our theory of stage-gated learning and to identify learning approaches to test these hypotheses for our empirical studies. Note that these hypotheses and their underlying conceptualizations are silent as to whether the effects of narrative processing and imagery coding on memory are independent or not. They are developed from two independent literature streams, and we do not see any reason in those literatures to think that they are jointly necessary. However a more nuanced future conceptualization of these and other elements of holistic processing may find otherwise.

\section{STUDY 1: EXPLORATORY DISCUSSIONS WITH MASTER SOMMELIERS}

Here we investigate whether and how taste experts believe they show a progression from analytic to holistic processing in their own learning. Even if holistic processing is important, it is not clear how that processing looks in the context of learning how to taste. In the tradition of naturalistic decision researchers studying expertise (Klein 1998), we use qualitative semistructured interviews with experts to identify important strategies in both the path followed in their own training as they recalled it, and in their training of novices. As a means to get them to think more broadly about their learning evolution a picture-elicitation deep metaphor approach was used for these interviews for uncovering tacit knowledge (Heisley and Levy 1991; Zaltman 
1997). Beilock (2010) says one of the curses of expertise is that experts may not be in touch with their own learning style, so such an in-depth technique was warranted.

The Master Sommelier diploma is the highest distinction a professional can attain in fine wine and beverage service. The process takes years of study and examinations involving blind tasting and theory. Currently there are only 229 people in the world that have obtained this title. Further, as the Court of Master Sommeliers has endorsed "the grid," a deductive, learning technique that focuses on analytical skills, this context serves as a good starting point to discern the role of analytic versus holistic approach to learning of an ambiguous product (see figure 1). This grid breaks the taste experience into parts, from color to aroma to taste. This is the only formal teaching mechanism used within this society to teach wine evaluation.

Insert figure 1 about here

Method

Interviews were conducted with 10 Master Sommeliers ( 9 male, 1 female) from three metropolitan areas (San Francisco, Las Vegas, and New York City). See Table 1 for participant background. A Master Sommelier colleague made the introductions for the interviews.

To the participants, s/he was an academic researcher interested in understanding the development of expertise in wine. In the initial contact, about seven to ten days before their oneon-one interviews, participants were asked to bring to the interview six to eight images of "your thoughts and feelings about wine expertise, with particular focus on blind tasting." Participants 
brought in images from newspapers, magazines and the Internet and they told stories about how these images represented their thoughts and feelings about how they blind taste and how they learned to be successful with their tasting. Participants were encouraged to talk about how the images were different or similar to each other. They were encouraged to discuss missing images (i.e., pictures they would have liked to bring in). Each interview lasted roughly 90 minutes.

Insert table 1 about here

Analysis

The interviews were audio-taped and transcribed verbatim. The resulting data included 280 pages of text. The interpretation of the interviews was discovery-oriented (Wells 1993). The approach to the data analysis is grounded in rigorous interpretive research procedures, including individual analysis, repeated iterations, and part-to-whole comparisons (Spiggle 1994; Thompson 1997). The authors discussed emerging interpretations, challenged each other, and ultimately jointly created the interpretations that follow.

Results

Our results follow the progression towards expertise using Anderson's two-stage model. Stage One: Obtaining Declarative Knowledge. Masters spoke both about their own initial learning as well as how they approach teaching students. In this stage what was important was 
providing students a conceptual framework and a vocabulary. Jason: "I think he (novice) needs more of a framework if you will to his tasting. He needs that structure of saying, 'Okay, what am I tasting? I'm going to describe it. What does that mean? Okay and so here, let me show you my work. I've tasted this wine. It tastes like this...",

In the early stages of learning to taste, analytic tools were effective for helping novices approach their ambiguous tastings in a more systematic fashion. Young brought in an image of a ladder and said the adage "before you climb the ladder, make sure it's against the right walls" applies to wine tasting, and that the novice needed to make sure they had a solid structure to begin their tasting analysis. Theo discusses the history and usage of the grid, saying that wine people were tradesmen and they required an assessment technique that allowed them to differentiate wine quality in a consistent, objective manner. He compared it to a fishmonger who might use a particular set of features to assess fish quality. Theo said it was important to teach novices the deductive method: "Teaching the framework, first of all, I mean that's obvious. And, they have to, for us there's a lexicon and they have to learn that.” The wine aroma wheel was noted by Masters as a tool they employed initially to learn the language of wine (Noble et al 1987).

When the grid was mentioned by participants it was associated with analytic thinking styles. Young, for example, brought in a picture of a crime scene saying that "there is a lot of evidence and clues (in the glass) so I often approach the wine as if I was a homicide investigator by going to a scene where there may or may not be a body." Jason also discussed the analytic approach of wine as a logical problem: "So if it's X, Y, Z, P, D, Q, therefore it must be T. So you have to be able to - you have to be able to make that statement and defend it. It's almost like writing a research paper or something like that." 
This first phase of learning is well understood by researchers and tools have been successfully developed to enhance this process. There is no clear prescribed path toward the next stage of learning. Thomas says the expert moves beyond the abstract language descriptors and the grid, calibrating to their own personal software which allows more intuitive tuning to the experience. "We take our own personal experience and put it into that framework, so different smells and our own physiology it gets translated into different things for different people. So, the bones of the thing are the same ... but everybody paints the lines differently." Maggie said that when she first started tasting she was intent on trying to figure out what she was smelling and what she was supposed to taste and she didn't get to the personal aspect of self-discovery until later in the process. She said it took her a long time to create images and differentiate aromas and smells. "First it just kind of smells like wine, and then maybe it's like one or two things and you learn, 'Oh, oak smells like vanilla. Okay, now I know that's what I'm smelling there."

How this more intuitive, creative process develops is unclear. Thomas, who was in charge of the educational program for the Court said of their training methods: "we focus very much on some specific aspects of the experience, but very, very little is talked about how we physically and mentally approach the experience. I grant it, it's anecdotal, but I feel like I've seen substantial information that tells me if people don't have this when they approach the wines, then they're not necessarily using all their faculties to the best of their ability and necessarily interacting with the wines as best they could... this grid really exemplifies that part of the experience that perhaps happens more consciously when you approach the wines. But not that space that happens more subconsciously when you're actually tasting the wines." We suggest this movement from stage one to stage two involves using more holistic processing. 
Stage Two: Tuning Toward Perceptual Experience. Rather than their training continuing down a path of more and more analysis, at some point our informants reported an "aha" when they realized they needed other approaches to advance their tasting skills. Our experts appeared to conclude that reliance on the grid and tools like the aroma wheel could be harmful, used as crutches, rather than allowing the taster to fully experience and understand the taste. Theo: "They (tasters) ride this really fine-line between utilizing all that past experience and also not letting it cloud, prejudge or cloud their assessment.... using all that wonderful knowledge and experience you gain, but also coming to it not with any preconceptions about what may or may not be." James: "There's an awful lot of novice-to-intermediate-plus tasters that are really regurgitating textbook stuff or stuff they heard another taster say and to me often has no meaning." The Einstellung effect can set in. Kris: "I see that people can put a square block into a round hole and try to do that very often, 'cause they'll get a one whiff without getting all the way to the end, and then just make their mind up that this is what it is."

Yang: "I can tell you that I remember first getting into it; it was all about, oh, memorizing the boxes and just hitting the grid, hitting the grid--as opposed -letting the wine speak for itself, I was speaking for the wine, almost like making up descriptors, just 'cause I thought I was filling in the boxes." He says his "aha" moment was when he realized that his fancy vocabulary wasn't conveying the actual taste experience in a meaningful way to his customer. Igor says the more abstract, non-meaningful descriptors come about when students just follow the grid. Doug expressed his discontent with some of the abstract terms used in the description of wine and the focus on accuracy of getting the wine right. He says while the grid is helpful in getting students to realize the complexity of wine, over time the expert learns to trust more gut instinctual aspects associated with their tasting. 
If not language, then what strategies do those on the road to expertise use? Ronald showed a Rorschach image to express what he sees when he tastes: "When I evaluate a wine, they tend to have shapes that on the nose, when I smell a wine, often a shape, perhaps not this detailed, a little bit more simple in terms of its shape, but an image like this tends to pop up often here." Maggie too says she has images come to mind as she tastes and she wanted to find a girl with a bubble over her head with dancing Bazooka gum to represent the types of images she sees when she tastes something like the vanilla gum (such as oak). Doug sees it more as a video: "Occasionally there will be an image of something, but it's more likely video than still image, if you will, that I'll remember an experience. And I like to kind of convey that to students as well that I'm on a hike and I hear the eucalyptus leaves crunching underneath my feet and I look down and I see these weird, long leaves, and I'm looking around and I'm seeing the trees and I'm smelling the smell that's coming out of the leaves, and there's cabernet sauvignon, that I've created associations."

Theo discusses the importance of images over words for tasting: "I'd be curious just to hear out of her mouth [Ann Noble, wheel developer] how she experiences wine. Because, she's done a great job of creating this wheel and it's full of what? Words. So, does she, when she personally tastes, what happens in her brain? There has to be images. I don't - I shouldn't say there has to be, but I don't think a word necessarily does a good job of describing the aroma that you're experiencing." Ted describes how using mental imagery works during tasting: "At some point we mentally step back from the entire map of the wine to review all the images with the idea of evaluating, remembering and hopefully enjoying the wine. Perhaps the sum total of such an experience is why good tasters rarely confuse one grape/style of wine for another-because the recognition and memory is based in multiple senses or what is often called a synesthesia." 
The decompositional approach to the analysis was also remarked as losing touch with the essence of the wine taste. The lack of emotion involved in using the grid structure in particular was noted by Ronald as one of the problems with its ability to capture the experience: “It's kinda like - well, it's not like playing music, because if you play music you need emotion in it, right? But when you're breaking down music, there's not much emotion involved. Let's say you're trying to transcribe music. Really, I mean, where's the emotion there if you're trying to transcribe it with sheet music?" Young uses music to help distinguish wines in more holistic ways, in terms of classical guitar styles. "In classical guitar there are two schools just very generally - a cedar top guitar and a German spruce top guitar. And the cedar top guitars are much more open. As soon as you purchase them they have this kind of round sweet note and have more booming bases. And so I always associate that with like a New World wine. It has more oak, it has rounder fruits, it's more supple and it's kind of syrupy and sweeter notes. But a German spruce top guitar, they tend to be more percussive and they tend to be - have more range of tone colors and they take much - like sometimes up to 20 years to really break in and open up. And so I've always associated those spruce top guitars with European wine. Because they seem more taut and a little bit more delineated."

Visual imagery allows the experts to both mentally organize current sensory data and compare that to information stored in memory. Ted says he mentally views the level of tannin, acidity, and alcohol for a wine as he's tasting and then brings up past prototypes that best "match." To assemble a prototypical taste for the mental comparison, experts need a way to integrate and organize their taste experience. The usefulness of narrative for this purpose was conveyed by experts in several ways. Jason brought in a picture of an Indiana Jones movie poster and said that when he thinks of describing a wine he thinks about what the headline should be, 
and what the supporting points are. "What's the most important thing, what's the star of the show, who are the supporting actors and who don't even get their name on the poster?" Kris compared it to a three-minute song on the radio: "You know the overall structure, 'so now let's put some meat of the bones so we can paint an image, cause you wanna tell a story when you describe the wine." He went on to describe the different characters that wine grapes can take representing different areas in Burgundy, with Volnay represented as elegant and precise like a ballerina, and Pommard "reliable, always on time and delivers, like truck driver, but not so pretty, and sometimes a bit dirty."

Ronald has used his shape skill to teach others to create a holistic impression of a wine. He teaches students to think of the wine taste as a shape evolving from aroma to finish. Kris said that he related to that idea: "I can see that. I can see ... it being like spiky or being like smooth. Like I can feel textures. Textures make sense. Shape of malolactic fermentation, so - like round. Round. Like an egg."

The purpose of removing these more abstract barriers (language, grid) to the perceptual experience was to allow the taster to get closer into the experience. Ted called this the "beginner's mind" so that they could be open to experience the taste. He brought an image of Curious George to represent this state. Masters said they needed to get in a "zen-like" state of mind for their evaluation, with Theo bringing the image of Buddha: "it's a very meditative kind of experience. I practice some Zen meditation, so I could put a picture of Zen in there. But, for me you have to have a certain degree of discipline and focus when you kind of approach the glass." James said it was critical for his tasting that he had time to "listen" to the images during his tasting and taking the time to "see" the wine. Young: "I guess what I try to do is to be inside the glass even though I'm imposing myself on the glass. But I try to be immersed in the glass 
and then come out of it. ... Kind of that's maybe a metaphor for being inside a giant pool of the wine."

Discussion

The experts reported that learning to taste is stage-gated, as suggested by our first hypothesis. As current research on consumer learning for stage 1 suggests, using analytic tools like the grid and aroma wheel can be effective for novices. However, the experts also reported that during their training they reached a point where they felt it was necessary to break away from this analytic approach and to engage with the wine more holistically which allowed them to "get close" to the taste experience, allowing tuning for stage 2 learning. Their holistic approaches involved imposing a narrative structure and employing visual imagery. The experts came to their holistic approach through the current "analytics hypothesis" whereby their insights emerged through practice. Our interest is whether enthusiasts can be taught this holistic approach rather than waiting for such insight to occur. A promising avenue to incorporate both the narrative and visual imagery to the taste evaluation experience was to think of the wine's overall shape, to have them draw it as Ronald related.

\section{OVERVIEW OF THE EXPERIMENTAL STUDIES}

To test our hypotheses, we have enthusiasts evaluate hedonic products like wine, coffee, beer and chocolate either using the traditional analytic grid and aroma wheel leading to a verbal evaluation, or by thinking about the experience holistically as a shape, and conveying that 
visually as a drawing. Both techniques are intended to help the consumer create an impression for later use in decision making: we want them to code the sensory experience into memory. The analytic approach has been discussed by other researchers (LaTour and LaTour 2010; Maciel and Wallendorf 2017), and while the holistic approach is newer to the consumer research it builds on our qualitative findings.

In our studies we define enthusiasts as those who have interest and experience with the target product, a minimum of five years tasting and some educational involvement. We define novices as those who have an interest in the product but no significant experience or training, and experts as those who have studied the product for at least 10 years and have received industry recognition for their taste expertise (as in credentials). These segments are akin to both Melcher and Schooler (1996) and LaTour and LaTour (2010) in their definition of novices, but more rigid for defining enthusiasts and taste experts as we desired our intermediates to be on the path towards expertise with some training rather than just frequent consumption, and our experts to be those who have clearly mastered stage 2 learning.

The scope of our empirical work needs to be delimited: although the theory is general, we test it by asking how an enthusiast can be induced to perform at expert levels in a narrowly prescribed portion of the expert field, which is the ability to identify a product tasted from an array of similar others (as what one might do in a blind tasting context). We do not tackle the more ambitious task of inducing an enthusiast to follow the whole development path to expert. We want to get enthusiasts to perform tasks at close to expert levels, not to become expert. Our justification is first that it can be tested within a lab setting, and second that if we can find evidence for the theory in this limited task we will be making progress toward the larger task. 
Whatever it takes to get an enthusiast to perform one task with the skill of an expert is, we propose, suggestive of what it would take across all tasks.

In our first study with enthusiasts (study 2) we set the groundwork for defining holistic processing in a taste context by varying the modality of representation at encoding (visual, verbal) and the composition (narrative, decompositional) aspects of the learning approach with our dependent measure memory performance. In study 3 we investigate cognitive transportation as the process that allows the enthusiast to get closer to the taste experience when using a holistic approach. Our hypotheses regarding the benefit of holistic processing focus on the enthusiast learner; we suspect that novices and experts will react differently to the learning interventions (Melcher and Schooler 1996). In study 4 we test for our stage-gated theory of hedonic learning (hypothesis one) with enthusiasts and novices, and predict that the holistic processing approach that has been so effective for enthusiast, will not be as effective for novices. Novices will benefit most from using verbal representation and decompositional process to initiate their declarative knowledge for stage 1 learning. In their case, then, a learning approach that promotes analysis will benefit them more so than one that promotes holistic processing. Our claim that this holistic approach takes enthusiasts closer to expert performance is tested in study 5 . In that study we expect those who have already obtained expertise to perform better overall and not be impacted by the type of learning approach as much as the enthusiast.

STUDY 2: DEFINING HOLISIC PROCESSING IN TASTE: ROLE OF MODALITY AND NARRATIVE 
In this study we look at two potential factors that may influence holistic processing: narrative and visual imagery. We vary the narrative aspect by having them think of the experience as a story/picture unfolding, or to analyze the individual parts of the experience. We vary the modality by which they record their thoughts (verbal or visual) as a means to promote more/less imagery. We have them rate their learning approach on a holistic scale. We assess the effectiveness of the learning approach by how well they later recognize the sample they tasted from a set of five similar taste experiences.

Method

Sample. One hundred six wine enthusiasts (80 female, average age 43, range 25-72) and 118 coffee enthusiasts (79 female, average age 43, range 21-80). Recruiting targeted enthusiasts that were learning about the featured products. Both groups were non-students and inclusion criteria involved consuming the target product for a minimum of five years though average much higher $(M=19.1=$ wine, $M=22.6$ coffee $)$. They were paid for their time. The design was 2 composite approach (decompositional, narrative) x modality (visual, verbal) x 2 product (coffee, wine).

Procedure. Participants came to a lab and were told they will be evaluating a wine (or coffee) and answering questions about their consumption. They were presented a target wine (coffee). They were given one of four instructions as they tasted the product (see Appendix A). In order to keep the conditions as parallel as possible each group was asked to focus on three aspects of their experience: aroma, texture and finish. In order to encourage involvement in the 
tasks they were told that an expert would be reading/assessing their drawings/comments. After the instructions were given, each group had five minutes to complete the task.

Several measures immediately followed the evaluation exercise: We had them state their agreement/disagreement with statements regarding holistic processing tendencies (that were converted to this particular context, adapted from Bhargave and Montgomery 2013): " 1 . I used the whole taste, rather than its parts, to understand the wine (coffee). 2. I found it to be more important to pay attention to the whole temporal experience than its parts to understand the wine (coffee). 3. I believe the taste experience of wine (coffee) is greater than the sum of its parts. 4. I found it more important to pay attention to the whole context rather than the details in the wine (coffee) taste experience. 5. I believe in tasting it is not possible to understand the parts without considering the whole picture. " These were summed to form a Holistic index after finding the items loaded on to one factor with Cronbach alpha $=.9$.

To rule out alternative explanations for recognition of the target sample, we compared the learning sessions on task valence, vividness, and involvement, as well as participants' mood, all measured on 7-point scales. To assess valence, participants indicated how positive or negative the evaluation task was to them (very negative/very positive). Vividness was measured using a two-item scale (dull/vivid, boring/interesting). Involvement was measured using a three item scale (very uninvolved/very involved, concentrating very little/concentrating very hard, paying very little attention/ paying a lot of attention). Mood was measured using the 10 -item International Positive and Negative Affect Schedule Short Form (Thompson 2007).

Participants were presented with a memory recognition test. They were asked to identify the wine (coffee) they had earlier tasted from an array of four similar others on a placemat. For each of the samples, participants rated their confidence that it matched their earlier taste on a 
scale where 1 = definitely not the wine (coffee) tasted earlier, $4=$ just guessing, and $7=$ definitely the wine (coffee) tasted earlier (from Melcher and Schooler 1996; LaTour and LaTour 2010). A discrimination score was computed by taking their confidence rating for the actual product subtracted by the average of their confidence for the other products, so that a perfect discrimination score would be 6 , no discrimination would be 0 , and a negative number signified that one of the distracters was rated as a match with more confidence than the actual one. Participants were then forced to choose one of the five wines (coffees) to represent their earlier tasting (and this was used for an accuracy measure). The order of presentation on the placement was varied in four ways across conditions, and found to have no significant effect on recognition.

Results

Manipulation Check. The narrative conditions were asked to view the experience as a whole to create a visual or verbal story while the decompositional conditions were asked to break it up into parts. Drawing should also induce more holistic processing than writing because it employs a visual representation. In order to check on our manipulations, we ran GLM with product, composition, modality, their interactions (product $\mathrm{x}$ composition $\mathrm{x}$ modality) as independent variables and the Holistic index as the dependent variable. The overall model was significant at $F(7,215)=3.05 p=.004$; compositional approach significant at $F=7.9 p=.005$, with the $\mathrm{M}_{\text {Narrative }}=25.6$ significantly higher than $\mathrm{M}_{\text {Decompositional }}=23.5$; modality significant at $F$ $=12.0 p=.0007$, with $\mathrm{M}_{\text {Visual }}=25.8$ significantly higher than $\mathrm{M}_{\text {Verbal }}=23.3$. We expected (and found) no significant difference across product categories $(F=.75)$ nor significant difference in the interaction $(F=.25)$ so the data was combined for the main analysis. 
We expected that our manipulation was influencing the manner in which participants approached the product during their evaluation (more/less holistically). All participants were enthusiasts consuming a product they enjoyed and the sessions all had them evaluate in a goaloriented manner. We tested alternative explanations for our learning tasks in terms of influencing consumer processing, and found mood, involvement, valence, vividness, and were all nonsignificant with Fs $<2$.

Memory Performance. Hypothesis three says the visual approach would be more beneficial than the verbal method. Our results are supportive of this hypothesis, with an effect of modality, with the visual conditions outperforming the verbal ones $\chi_{(1, \mathrm{~N}=223)}^{2}=6.1 p=.01$ (58.9\% Visual versus $42.3 \%$ Verbal). Hypothesis two predicts the narrative method would outperform the decompositional method, and this was also found, $\chi_{(1, \mathrm{~N}=223)}^{2}=22.6 p<.0001$ (66.4\% Narrative versus 34.5\% Decompositional). See figure 2 for the results.

Insert figure 2 about here

The discrimination measure showed similar support for our hypotheses. GLM was run with composition, modality and their interaction as independent variables, the discrimination score as the dependent variable (with higher scores indicating greater discrimination). The overall model was significant, $F(3,219)=8.9 p<.0001$; Compositional approach significant at $F$ $=21.03 p<.0001$, with Narrative higher than Decompositional, $\mathrm{M}=2.4$ versus $\mathrm{M}=.93$, and modality was also significant $F=3.9 p=.05$, with Visual higher than Verbal, $\mathrm{M}=2.0$ versus $\mathrm{M}$ $=1.4$. The interaction was not significant $(F=1.8)$, though the Visual Narrative condition was 
significantly higher than the other conditions, $\mathrm{M}_{\text {Visual Narrative }}=3.0, \mathrm{M}_{\mathrm{Visual} \text { Decompositional }}=1.0$, $\mathrm{M}_{\text {Verbal Narrative }}=1.9, \mathrm{M}_{\text {Verbal Decompositional }}=.83$.

Discussion

The purpose of this study was to test our hypotheses regarding the impact of narrative and visual imagery to promote holistic processing and observe the effect on memory performance compared to more traditional analytic methods. As per hypothesis three we found the visual method more effective than the verbal one, and that those who used a narrative (rather than decompositional) strategy resulted in better memory performance (hypothesis two). In the shape drawing condition where the participant created a visual narrative (an example appears in Appendix B) they had the highest overall performance.

We were able to demonstrate the narrative and visual approaches both led to more holistic mindsets rather than other alternative paths. However, while the holistic scale did capture some of the effects of our learning tools and served as a manipulation check, this index was not a good measure for predicting later memory performance (with index not significantly correlated with accuracy, $r=.15$ and significant but low with discrimination $r=.22$ ). We suggest this is because the index measures overall mindset toward holistic processing rather than the effects of holistic processing (being closer to the experience).

The narrative format allows the consumer to extract meaningful information and patterns from their taste experience. The Master Sommeliers discussed the importance of "getting close" to the taste experience, and one of the criticisms of using the wine aroma wheel is that it distances the taster from the actual taste experience by imposing language on a sensory 
experience that might not necessarily be translated in that manner. We believe having consumers draw the wine's taste results in better memory performance because it allows for more direct perception.

Our next study considers the process by which our shape drawing task works to improve taste memory. Cognitive transportation entails a lack of self-awareness such that those who are transported into a narrative world may not notice events happening around them. Good narratives transport audiences into a story; we believe a similar result would appear in this context where the approach that transports the consumer into the taste experience results in better memory performance.

\section{STUDY 3: TRANSPORTING INTO TASTE}

In this study the narrative nature of the task across the verbal and visual conditions remains constant as we have enthusiasts consider the taste unfolding either as a story or as a picture to induce more holistic processing. We predict that enthusiasts who are "transported" into their taste experience will create a stronger memory of that experience, and that those who draw will experience greater transportation because they do not have to have the additional layer of language to convey their taste experience (per hypothesis three).

Method

Sample. The sample for this study includes craft beer and chocolate enthusiasts. Inclusion criteria for both groups involved at least five years' experience tasting in their specific domain 
and some training. The craft beer participants were recruited through several means: a local craft brewery, a meetup site, beer making class, and distribution list to local community members. In total 71 craft beer enthusiasts participated (35 female, average age 25 with a range from 21 to 51). The chocolate participants were self-defined "foodies" with particular affinity for chocolate. They primarily were students in a hospitality program focusing on food and beverage. There were 122 participants in the chocolate study (69 female, average age 19 with a range 18 to 22 ). Both groups were paid for their time.

Procedure. The procedure was similar across products: participants came in as groups and were given a brief background about the artisanal product and necessity for evaluation. The craft beer group was told about different types of beers (lagers, ales) and that they would be focusing on evaluating an American IPA. The target beer had citrus and pine aromas, a light body, and a bitter finish. The chocolate groups learned how different chocolates are made (dark, white, milk) and were told that they would be tasting an artisanal dark chocolate. The target chocolate contained cranberries and almonds. Both product groups were given either a visual or verbal narrative strategy for evaluating the product and were instructed to "write (draw) a summary story of the product's taste."

Consistent with the approach adopted by Escalas (2007) to measure cognitive transportation, we measured each component of transportation. We measured the cognitive engagement component (i.e., the level of mental involvement in the tasting) with "I was mentally involved in the tasting experience when I wrote (drew) the summary story." The emotional component was measured with "I was emotionally involved in the tasting experience." Finally, the mental imagery component was measured with "I could picture myself in the tasting 
experience when writing (drawing) the summary story." All questions were measured on a seven-point scale $(1=$ strongly disagree, $7=$ strongly agree $)$. The correlations among the three measures were all significant $(p<.01)$ and ranged from $r=.73$ to $r=.78$. with Cronbach's $\alpha=$ .9. This evidence suggests the three questions reflect the same underlying construct; thus, we averaged the response to these three questions to create a composite measure of taste transportation.

Our dependent variable of interest was memory performance. The recognition test for both groups included the original taste and four other similar tastes (for craft beer, four IPAs that varied on hops and flavor quality, for chocolate four other dark chocolates that contained different fruit and nut additions). The craft beer group members performed their memory tests after a fifteen-minute delay as in study 2, the chocolate group members came back a week later to do their memory tests. We combined the two product groups for our analysis after finding no significant interaction on our main measures.

Results

Transportation. Per hypothesis three, we expected that the visual condition $(\mathrm{M}=15.6)$ would be higher in transportation than the verbal condition $(\mathrm{M}=13.2)$, and this was found to be significant, $t(192)=4.2 p<.0001$.

Memory Performance. In the recognition test, accuracy was overall higher for those in the visual conditions than the verbal conditions $-60 \%$ versus $33 \%$ significantly different at $\chi^{2}(1$, 
$\mathrm{N}=194)=13.8 p=.0002$. The visual condition also outperformed the verbal on discrimination, $\mathrm{M}_{\text {Visual }}=2.01$ versus $\mathrm{M}_{\text {Verbal }}=1.02, t(192)=3.02 p=003$.

Mediation Analysis. We predict that the holistic processing guided by the drawing procedure is effective for enhancing taste memory because it more fully allows for periods of direct perception. As the Masters indicated for their own evaluation, a task that draws a person closer to the taste experience should be most effective. Within the context of taste learning we suggest that these benefits are most captured through the transportation scale. We previously demonstrated that there was a significant relationship between learning approach and transportation; and learning approach and memory recognition. We ran a regression and found that the transportation scale was significantly related to both accuracy, $(F=107.39 p<.0001)$ and discrimination $(F=54.4 p<.0001)$.

Using a bootstrapping analysis (Hayes 2014, Model 4: 5,000 bootstrapped sample), we examined a mediation model, which included the transportation scale for the memory performance measures of accuracy and discrimination with the learning approach as the independent variable. We found significant indirect effects of transportation on accuracy $(b=$ $.1 .0, \mathrm{SE}=.29, \mathrm{CI}_{95 \%}, .53$ to 1.66$)$ and discrimination $\left(\mathrm{b}=.60, \mathrm{SE}=.15, \mathrm{CI}_{95 \%}, .33\right.$ to .94$)$. The transportation measure fully mediated the learning method for accuracy and discrimination (where the effect of learning was no longer significant for accuracy $z=1.5 p=.14$, and discrimination $t=1.3 p=.20$ ).

Discussion 
We found that the shape drawing task resulted in enthusiasts becoming more "transported" into their tasting experience which led to more accuracy in memory identification. The transportation scale fully mediated the effects of the learning approach on memory accuracy and discrimination.

Our main hypotheses regarding the benefits to this more holistic processing method has focused on the enthusiast. The consumer learning literature meanwhile has focused on the benefits to novices of analytic learning methods. However, no one to our knowledge has proposed that learning is stage-gated (our hypothesis one).

\section{STUDY 4: STAGE-GATED TASTE LEARNING}

In this study we focus on two distinct cells from study 2: the verbal/decompositional grid approach which has been traditionally taught to enhance analytic processing; and the visual/narrative approach which we have been found to induce more holistic processing. We predict that novices will benefit most from the analytic learning approach while enthusiasts will be more successful with a holistic approach, hypothesis one.

Method

Sample. We recruited for wine novices and enthusiasts. Novices were defined as those with interest in wine but no tasting experience, and enthusiasts were defined as those with interest and experience. To more specifically confirm and operationalize these categories we had participants fill out background information about their wine experience: how long they have 
been drinking wine, how often they drink wine, how many different wine styles they have tried, and whether they had participated in any wine education pursuits (either formal in a wine class or informal through online education or wine tourism). To be considered a novice the person had to be drinking wine for no more than three years (our mean was 2.4 ), consume wine infrequently (less than two times a month), was aware of and had tasted two or fewer wine styles, and most importantly, had not actively pursued any wine education. The novices indicated no awareness of either the formal grid analytic approach or the holistic shape drawing approach to wine evaluation. Most of the novices had just starting drinking wine, either because they were now of legal age, or because their tasting interests had evolved from drinking other types of alcohol like beer. Enthusiasts meanwhile did seek out knowledge about wine, reported drinking wine for more than five years (mean 7.5), and were aware of a minimum of five different wine styles and had broad tasting experience, and reported consuming wine a minimum of 4 times a month. The enthusiasts indicated awareness of the verbal/grid analytic approach to evaluation but no one reported being aware of the holistic shape drawing approach. Sixty-five percent of the enthusiasts had taken some wine education class, and the remainder indicated self-study using magazines, books, Internet. There was no significant difference in performance between these two types of enthusiasts (accuracy $50 \%$ for education group versus $48 \%$ for self-directed) and so they were combined as one enthusiast group. Seventy-two novices (mean age 23.5, age range 2157, and 59 females) and 72 enthusiasts (mean age 27.8, age range 21-61, and 55 females) participated in this study. Participants were randomly assigned to either a shape drawing condition, which had met our definition of holistic processing in previous studies, or the more traditional verbal/grid intended to induce more analytic processing. 
Procedure. Because our sample varied on background knowledge of wine tasting, we began this experiment with a broad introduction to wine, lasting ten minutes. Information about color, aroma, and structure were discussed. The grid and aroma wheel were presented as tools for the analytic group, while another group learned the holistic approach of drawing the shape. Both groups were told to focus on the aroma, taste and finish as they evaluated the wine. A practice wine (Pinot Noir) was given for them to evaluate. In the analytic group the moderator went through the steps of evaluation using the grid and showed how to use the wheel to find descriptors to write a note. Participants were asked to write a 3 to 5 -sentence tasting note about the taste experience from aroma to mouthfeel to finish using the grid and wheel as tools. In the holistic task participants were shown how to approach drawing the taste of the wine by using images. They were given a box of crayons and told to draw their impression of the wine from aroma to finish. The instructions and evaluation for both groups lasted for ten minutes.

Afterwards participants indicated whether the information presented was new to them. Background information about their wine experience was then obtained. Then they were given the target Zinfandel wine and five minutes to write (or draw) a description of how they experienced the wine's taste. They were told that they would be asked about this target wine later so to write/draw something that would help them remember the taste. After they had done their evaluation, they completed the holistic processing scale. They also rated how difficult they found the task as well as how much effort they put into their evaluation. They provided feedback about the learning session. The next day they came back for their memory identification task.

Results 
Manipulation Check. We predicted that the shape drawing task would lead to greater holistic processing than the verbal grid. We ran GLM with experience and learning approach and their interaction as the independent variables and the holistic index as the dependent variable. The model was significant, $F(3,140)=5.9 p=.0008$; only learning approach was significant, with the shape drawing higher $\mathrm{M}=23.8$ to $\mathrm{M}=20.9$ verbal grid, significant at $F(1,140)=14.3 p$ $<.0001$. Experience was not significant $(F=.43)$ neither was the interaction $(F=2.9)$

An alternate explanation for the effectiveness of one of the learning techniques is that it makes processing the wine easier (or more difficult). Additionally, if one session lead to greater effort by participants, that could also be a factor. We ran GLM with experience, learning approach and their interaction as independent variables and the effort and difficulty measures as dependent variables. Neither model was significant, Fs $<1$.

Memory Performance. As predicted in hypothesis one, novices were more accurate in the analytic verbal grid condition (29.7\%) than the holistic shape drawing condition $(11.4 \%), \chi^{2}(\mathrm{~N}=$ $72)=3.7 \mathrm{p}=.05$, and enthusiasts more accurate in the holistic shape drawing condition (66.7\%) compared to the analytic verbal grid $(36.1 \%), \chi^{2}(\mathrm{~N}=72)=6.7 p=.009$. See figure 3. Enthusiasts were also more accurate overall (51.3\%) than novices $(20.8 \%), \chi^{2}(1, \mathrm{~N}=144)=4.2 p=.04$. Type of learning tool was not significant, shape drawing $40.8 \%$ versus verbal grid $31.5 \%, \chi^{2} 1$, $\mathrm{N}=144=1.4 p=.2$.

A discrimination score was computed for each participant. GLM was run with experience, learning approach and their interaction as independent variables and the discrimination score as the dependent variable. The model was significant at $F(3,140)=5.8 p=$ 001. There was a crossover interaction where with the novices discrimination was higher in the 
analytic verbal grid condition $\left(\mathrm{M}_{\mathrm{Verbal}}=.5\right.$ versus $\left.\mathrm{M}_{\mathrm{Visual}}=-.45\right)$, and with the enthusiasts discrimination higher in the holistic shape drawing condition $\left(\mathrm{M}_{\text {Visual }}=1.8\right.$ versus $\left.\mathrm{M}_{\text {Verbal }}=.99\right)$, $F(1,140)=5.1 p=.02$. There was also a main effect of experience where the enthusiasts were overall more discriminating than the novices, $\mathrm{M}_{\text {Enthusiasts }}=1.4, \mathrm{M}_{\text {Novices }}=.08, F(1,140)=12.2 p=$ .0006. The learning approach was not significant, $F=.05$.

Insert figure 3 about here

Discussion

To novices both the analytic and holistic approaches to evaluating wine were new. Some novices indicated that this session was the first time they heard words like "finish" and "tannin" associated with wine. Novices in the verbal grid session reported that they "better understand the framework" and "now know what to look for in wine evaluation." This type of analytic learning approach allows them to break down the wine and make their evaluation more manageable. The novices found the holistic visual narrative fun and informative, but it did not help them better remember the taste. Enthusiasts, meanwhile, reported that the analytic verbal grid session was a "good refresher" to what they already knew and appreciated the practice. They were already familiar with the analytic approach. For the holistic condition the feedback was different, all enthusiasts indicating it was a new way to evaluate wine for them. Enthusiasts reported liking the drawing process it "because it comes closer to my taste experience" and that it "forced me to think about all parts of the experience and organically show it." One said it got him out of 
mindless evaluation where it "actually focused me on what the wine tasted like instead of slapping the bag." The results confirm hypothesis one that learning to evaluate hedonic products is stage-gated - novices did not benefit from the holistic learning approach as they had not yet embraced the lexicon and rules. Our next study tests whether or not this holistic approach is indeed getting the enthusiast closer to expert performance.

\section{STUDY 5: ENTHUSIASTS APPROACH EXPERTISE}

In this study our sample was both experts and wine enthusiasts. The task involves tasting two red wines. The wines were the same but one had some additional oak tannins added (the color of the addition was the same as the wine). This is a difficult taste discrimination exercise because visually the wines look the same (Hoegg and Alba 2007), they only differ on structural/taste properties. Within each level of expertise we offered either visual or a verbal evaluation tool as they taste the wines, where they were asked to either write a traditional verbal note or draw a picture. We predict that the enthusiasts will perform better (i.e. be more discriminatory) with the more holistic visual technique and approach expert performance when using this method. Experts meanwhile will have already learned how to holistically encode the experience so the technique will not be as important.

Method

Sample. The forty experts had obtained advanced certifications through the Court of Master Sommeliers or a similar organization and had been studying wine for at least ten years. 
The forty enthusiasts consisted of students who had taken a wine appreciation course and were interested in furthering their knowledge of wine. It was important that this group have some familiarity and interest with wine, but not the rigorous training of experts. As one might expect, the enthusiast students were younger than the experts (average age 25 versus 46), but no other overt differences like gender differentiated the groups.

Procedure. The task here involved comparing two versions of the same red wine, a Pinot Noir from California served in clear wine glasses. In one version, oak tannins were added which slightly altered the aroma, taste and mouthfeel of the wine (but had no effect on color). The other version was not altered. Participants were either asked to analyze and write a tasting note, or to draw a picture of each wine's taste. They were given five minutes to do this task. They then rated the wines comparatively on seven dimensions (flavor, acid, tannin, body, alcohol, finish, quality) where $1=$ not at all similar, 7 = very similar. Participants were asked whether they believed drawing or writing a note was more effective in communicating the wine taste.

Results

Perceptual Differentiation. The seven comparative scales were summed (flavor, acid, tannin, body, alcohol, finish, quality). Scales were reverse coded so higher numbers indicate greater discrimination between the wines (as the scales ranged from $1=$ not at all similar, $7=$ extremely similar). GLM with expertise (expert, enthusiast) and type of task (visual, verbal) and this summed comparative judgment as the dependent variable. The model was significant at $F(3,76)=6.8 p=.0004$. There was a main effect for the learning approach, where both the 
experts and enthusiasts reported a larger difference between the wines with the visual narrative instruction than the verbal tasting note instruction, $\mathrm{M}_{\mathrm{Visual}}=44.2, \mathrm{M}_{\mathrm{Verbal}}=39.46, F(1,76)=13.6$ $p=.0004$; and a main effect for expertise, where experts were overall more differentiating than enthusiasts, $\mathrm{M}_{\text {Expert }}=43.2, \mathrm{M}_{\text {Enthusiast }}=40.4, F(1,76)=4.7 p=0.03$. The interaction was not significant $(\mathrm{F}=2.2)$ but given our hypotheses we conducted post-hoc tests for the visual condition and found enthusiasts were no different from experts $(t=0.46)$, whereas in the verbal condition experts were more discriminatory than enthusiasts $(t=2.1 p=0.04)$. See figure 4 for the means.

Insert figure 4 about here

Discussion

As predicted, enthusiasts performed better with the holistic drawing approach and also approached expert performance when using that technique. Because experts have already grasped holistic understanding of the wine (as well as the language) the type of learning technique at encoding did not make as much of a difference. The shape drawing approach is not customary. When asked directly most participants 95\% (94\% experts, 95\% enthusiasts) said they would prefer writing notes about the wine. In fact, one expert questioned whether or not regular consumers would be able to grasp this concept, and another said that words were more universal, common and thus would be more effective for learning. This harkens back to Beilock's suggestion that experts are not aware of the strategies that might be most impactful to their own or others learning. 


\section{GENERAL DISCUSSION}

The traditional approach to learning (expressed as the "analytics hypothesis") is that novices, to become experts, need to engage in more and more analysis, and after a long period of time, emerge with the enhanced holistic ability seen by experts in their ability to quickly identify patterns (referred to as fluency, Ericsson et al 2007).

This paper proposes a different path to expertise. We claim that there are two stages to taste learning, analytical and holistic, and we claim that some progress must be made on the analytical stage before the holistic stage can begin. We claim that holistic learning is facilitated by attending to experience as a narrative event and by using imagery. We tested the claims in five studies.

The first study involved exploratory discussions with wine experts in which, tacking between their insights into their personal learning paths and theories of learning, our theory of taste expertise emerged. Studies 2 and 3 involved just enthusiasts. Study 2 found that enthusiasts' ability to recognize wine or coffee was enhanced by narrative over decompositional training, and whether they recorded the initial tasting with an image or verbally. Study 3 found that enthusiasts' ability to recognize beer or chocolate was enhanced more by recording the experience in an image than by verbal recording, mediated by their scores on a narrative transportation scale. Study 4 compared enthusiasts to novices. It found that enthusiasts' ability to recognize a wine was enhanced by holistic training, but novices' was not, where they demonstrated greater learning with an analytic approach. Study 5 compared wine enthusiasts to experts on a wine recognition task. It found that holistic instructions brought enthusiasts close to the performance of experts, while analytic instructions did not. 
In sum this research challenges the "analytics hypothesis," and suggests that a holistic approach offers people of intermediate ability a gateway to the quick pattern recognition that experts appear to engage in fluently. Figure 5 illustrates the process. The gray boxes suggest the learning approaches most helpful at each stage, while the white text identifies the associated cognitive processes. Note that holistic processing is found at the start and the end of learning, but the content and type differ greatly. Novices glean the surface structure and can be influenced by unimportant details, so that this holistic processing is superficial. They focus on concrete elements, such as similarities. Expert holistic processing identifies the deep structure of experience. To move from this more simplistic processing to the holistic gist that experts possesses involves learning how to extract relevant information (from analysis) and then synthesizing the information in a meaningful way.

Insert figure 5 about here

A New Lens on Consumer Learning and Expertise

Learn the rules like a pro, so you can break them like an artist.

— attributed to Pablo Picasso

The general idea that experts do not follow the rules to which the rest of us are slaves is not unfamiliar, but is difficult to document. Few if any studies have set out to follow a novice all the way to expert, a process that may take ten years of deliberate practice (Ericsson et al 2007). The problem is compounded by diminishing returns. Gladwell (2011) argues that it is relatively 
easy to entice novices into a new field of knowledge because they are rewarded by an early spurt of learning, but as the pace of learning slows, discouragement sets in. Wood and Lynch (2002) anticipated Gladwell: they found that acquisition of knowledge diminishes motivation to acquire more, so as consumers approach competence they learn at a slower pace than novices.

It is perhaps to be expected, then, that industries as well as scholars have relied on the analytical tools that produced the early spurts of learning - taste wheels, attribute checklists, vocabulary, and other analytical instruments - to induce learning to continue.

This research was inspired to abandon this analytical bias by a comment from an expert in Study 1, Ronald, who mentioned that he made use of a shape drawing tool to create a holistic impression of a wine. The research began atheoretically, as a program to test the effect of Ronald's shape drawing tool on wine recognition. Just as the microscope's lens showed biologists undertheorized phenomena, this lens led us to investigate theories of holistic processing. The path was fruitful but has hardly been exhausted, and should reward several directions of future work.

First, there is the analogy to the development of visual expertise. Most abstract painters first master figurative painting, and to abandon or riff on a form, one has to grasp its underlying principles. Similarly the shape drawing technique builds from underlying analytic principles, by removing their reliance on both language and decompositional thinking.

Drawing theorist Ruskin (1857/1991) believed the drawing process allows the artist to "see past" higher cognition so that they experience a "pure appreciation of natural fact." A later theorist of drawing, Tversky (2011), believes that drawing can be used as a "tool for insight" to facilitate knowledge acquisition and cognitive skills. Drawing may allow for analogical transfer. Some recent research on "doodling" (Schott 2011) reports that drawing activates a baseline 
default mode of cortical activity in an area of the brain that includes the medial temporal lobe, medial prefrontal subsystems and posterior cingulate cortex, which seems to be inversely related to activity in the "attention system" that governs goal-directed cognition. The research reports that doodling may enhance creative associations, problem-solving and memory (Andrade 2010). Recently in the analysis of big data, artists have been employed to find meaningful patterns in digital output (Carey 2015) showing that synthesis has been used effectively on other searches for insight. Future research might consider how doodling, or creating a Pictionary summary, may influence aspects of memory in domains beyond education. Research could explore holistic instruction in situations requiring co-production between brand and consumer, where the consumer needs to learn to apply particular knowledge and skills if a successful consumption experience is to result.

Second, there remains work to be done in extending from skill at recognition to enjoyment. We studied how people learn to be expert at recognizing hedonic products, not how they learn to extract enjoyment from them. Although Clarkson et al (2013) find that the two outcomes are not independent (people seek products from which they can accrue consumption knowledge,) the question of whether experts enjoy hedonic products more than enthusiasts and novices is largely unanswered. If the answer is yes then work needs to be done to decide how expertise informs hedonic gratification. Is the path a matter of enhanced capacity to attend to sensory stimuli, or is it a matter of self-presentation, or both?

Third, our research focused on the performance of people who were motivated to learn. However among people who want to engage with hedonic products there may be some who are not as learning-oriented as the enthusiasts studied here. Are our results sensitive to this individual difference? Perhaps not. We found that our novices in study 4, while not performing 
as well with the holistic approach as the analytic one in their memory tests, they did seem to enjoy the product more when they approached it holistically. Research in music appreciation has also found that having consumers focus on analytic ratings of their experience detracts from the overall emotional experience (Yingling 1962) suggesting that the goals as well as the background experience of the learner needs to be considered.

\section{Limitations}

In an ideal study, one would want to follow a cohort from novice to enthusiast to expert status and observe the changing dynamics of the learning environment. For practical reasons our experiments focused instead on several points in that path. Products may vary as to their complexity and influence how quickly consumers are able to move successfully from the analytic to holistic approach. Additionally the amount of time spent in the evaluation process itself may also factor in as to how much time is needed to progress from stage 1 to stage 2 . Enthusiasts will not achieve expertise in a singular session regardless of how optimal the learning tool. However our claim is that our research has uncovered an approach to training that could be incorporated into a more elaborate program of research. 


\section{DATA COLLECTION INFORMATION}

The first author is a certified sommelier through the Court of Master Sommeliers and was a student in the Master of Wine program and used her connections to get access to these elite group of tasters. The first author conducted the interviews with Master Sommeliers during Fall/Winter 2012/2013. Those were transcribed. Data were discussed and analyzed on several occasions by both authors. The first author ran and conducted the analysis for the experiments, the second author helped design those studies. Study 2 was conducted at the LEEDR lab at Cornell University with wine enthusiasts Spring 2016 and coffee enthusiasts Spring 2017. Study 3 was conducted at the Cornell Hotel School with Ithaca area beer enthusiasts Spring 2017 and chocolate enthusiasts in Fall 2015. Study 4 was conducted with novice and enthusiast wine consumers around the Ithaca, NY area in Spring 2017. Study 5 was conducted with wine enthusiasts at Cornell, and at a Master of Wine and Finger Lakes wine competition during Spring 2014 and Fall 2016. 
Visual

Decompos

Draw a picture of the component parts of the wine's taste. Use your box of crayons to help

itional you express these individual aspects of the taste. We will be asking you about this wine

Focus later on, so try to draw something that helps you remember the wine's taste.

Start breaking down the wine by assessing its aroma. Smell the wine and write a draw a picture of what you encounter. Do you smell fruit or spice or minerals? Or something else? Is the aroma intense or barely there? Use your box of crayons to represent the wine's aroma. Then taste the wine. How does the texture feel on your palate? Is it firm or smooth? Is it fullbodied or light? Draw a picture of the wine's texture. Then notice the wine's finish after you swallowed- does it drop off quickly or stay awhile? Is it bitter or sweet? What flavors do you notice in the finish? Draw a picture of the wine's finish.

Narrative Draw a picture of how you experience the wine's taste over time. Use your box of Focus crayons to help you express its effect over time. We will be asking you about this wine later on, so try to draw something that helps you remember the wine's taste.

Show time as a line from left to right in the middle of the sheet of paper. On the left show the initial encounter and on the right the finish. Draw a shape to show how the taste changed over time. For instance a thin line at the initial encounter might grow into a circle and then end with extended jagged lines to indicate a wine that started tight and then opened up and had a round texture and ended with a long rough finish. Use your box of crayons to help you convey your story with the images representing the visual flow of your taste experience.

Write a description of the component parts of the wine's taste. Use the wine aroma wheel to help you express these individual aspects of the taste. We will be asking you about this wine later on, so try to write something that helps you remember the wine's taste.

Start breaking down the wine by assessing its aroma. Smell the wine and write a description of what you encounter. Do you smell fruit or spice or minerals? Or something else? Is the aroma intense or barely there? Use the wine aroma wheel to represent the wine's aroma. Then taste the wine. How does the texture feel on your palate? Is it firm or smooth? Is it fullbodied or light? Write a description of the wine's texture. Then notice the wine's finish after you swallowed- does it drop off quickly or stay awhile? Is it bitter or sweet? What flavors do you notice in the finish? Write a description of the wine's finish.

Write a description of how you experience the wine's taste over time. Use the wine aroma wheel to help you express its effect over time. We will be asking you about this wine later on, so try to write something that helps you remember the wine's taste.

Record changes in your impression of the wine from the initial encounter to the finish, using the wine aroma wheel to help you find words. For example you might say, "At first the wine was thin but on my palate I experienced a gush of berry fruit that awakened my senses, and then, for several seconds after I swallowed, the experience of fruit gave way to a sensation of sandpaper in my mouth." Use the wine aroma wheel to help you convey your story with descriptors representing the narrative flow of your taste experience. 
49

APPENDIX B: SAMPLE SHAPE DRAWING

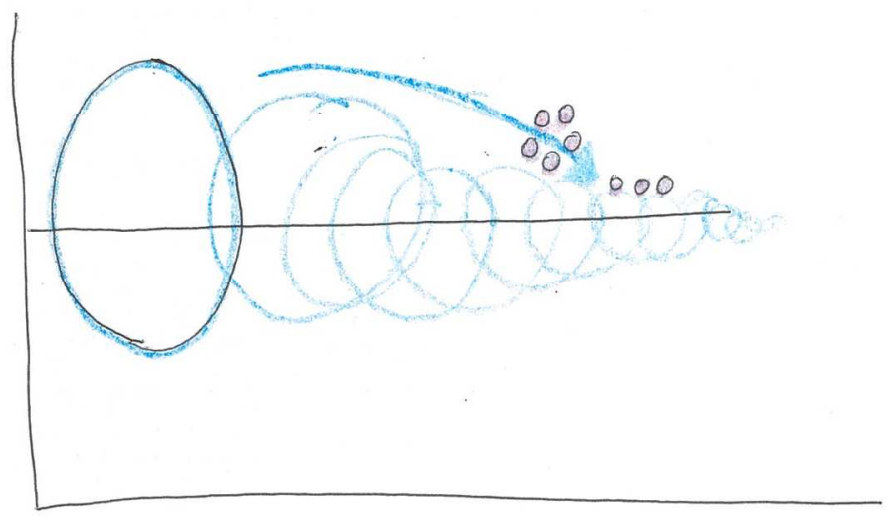


Visual

Decompos

Draw a picture of the component parts of the wine's taste. Use your box of crayons to help

itional you express these individual aspects of the taste. We will be asking you about this wine

Focus later on, so try to draw something that helps you remember the wine's taste.

Start breaking down the wine by assessing its aroma. Smell the wine and write a draw a picture of what you encounter. Do you smell fruit or spice or minerals? Or something else? Is the aroma intense or barely there? Use your box of crayons to represent the wine's aroma. Then taste the wine. How does the texture feel on your palate? Is it firm or smooth? Is it fullbodied or light? Draw a picture of the wine's texture. Then notice the wine's finish after you swallowed- does it drop off quickly or stay awhile? Is it bitter or sweet? What flavors do you notice in the finish? Draw a picture of the wine's finish.

Narrative Draw a picture of how you experience the wine's taste over time. Use your box of Focus crayons to help you express its effect over time. We will be asking you about this wine later on, so try to draw something that helps you remember the wine's taste.

Show time as a line from left to right in the middle of the sheet of paper. On the left show the initial encounter and on the right the finish. Draw a shape to show how the taste changed over time. For instance a thin line at the initial encounter might grow into a circle and then end with extended jagged lines to indicate a wine that started tight and then opened up and had a round texture and ended with a long rough finish. Use your box of crayons to help you convey your story with the images representing the visual flow of your taste experience.

Write a description of the component parts of the wine's taste. Use the wine aroma wheel to help you express these individual aspects of the taste. We will be asking you about this wine later on, so try to write something that helps you remember the wine's taste.

Start breaking down the wine by assessing its aroma. Smell the wine and write a description of what you encounter. Do you smell fruit or spice or minerals? Or something else? Is the aroma intense or barely there? Use the wine aroma wheel to represent the wine's aroma. Then taste the wine. How does the texture feel on your palate? Is it firm or smooth? Is it fullbodied or light? Write a description of the wine's texture. Then notice the wine's finish after you swallowed- does it drop off quickly or stay awhile? Is it bitter or sweet? What flavors do you notice in the finish? Write a description of the wine's finish.

Write a description of how you experience the wine's taste over time. Use the wine aroma wheel to help you express its effect over time. We will be asking you about this wine later on, so try to write something that helps you remember the wine's taste.

Record changes in your impression of the wine from the initial encounter to the finish, using the wine aroma wheel to help you find words. For example you might say, "At first the wine was thin but on my palate I experienced a gush of berry fruit that awakened my senses, and then, for several seconds after I swallowed, the experience of fruit gave way to a sensation of sandpaper in my mouth." Use the wine aroma wheel to help you convey your story with descriptors representing the narrative flow of your taste experience. 
Role of Information Processing in Impulsive Buying", in NA - Advances in Consumer Research Vol. 23, eds. Kim P. Corfman and John G. Lynch Jr., Provo, UT : Association for Consumer Research, 463-469.

Carey, Benedict (2015), “Learning to See Data,” New York Times, March 27 http://www.nytimes.com/2015/03/29/sunday-review/learning-to-see-data.html?_r=0 accessed March 21, 2016

Clarkson, Joshua A., Chris Janiszewski, and Melissa D. Cinelli (2013), "The Desire for Consumption Knowledge,” Journal of Consumer Research, 39 (April), 1313-1329.

Cozolini, Louis (2001), The Neuroscience of Psychotherapy, NY: W.W. Norton, 166-9.

Deighton, John, Daniel Romer and Josh McQueen (1989), “Using Drama to Persuade,” Journal of Consumer Research, 16 (3), 335-343.

"Demand for Wine and Spirt Education at an All-time High," Drinks Business, August 3, 2017, https://www.thedrinksbusiness.com/2017/08/demand-for-wine-and-spirit-education-atrecord-high/

Ericsson, K. Anders, Michael J. Prietula and Edward T. Cokely (2007), "The Making of an Expert," Harvard Business Review, July-August, 1-9.

Escalas, Jennifer Edson (2007), "Self-Referencing and Persuasion: Narrative Transportation versus Analytical Elaboration," Journal of Consumer Research, 34 (March), 421-429.

Fitts Paul. M. (1964), "Perceptual-motor Skill Learning,.” In: Melton AW, editor. Categories of Human Learning. NY: Academic Press; 243-285.

Geeves, Andrew, Doris J.F. Mcllwain, John Sutton and Wayne Christensen (2014), “To Think or Not To Think: The Apparent Paradox of Expert Skill in Music Performance," Educational Philosophy and Theory 46:6, 674-691. 
Gibson, Eleanor (1969), Principles of Perceptual Learning and Development. New York: Appleton-Century Crofts.

Gladwell, Malcolm (2011), Outliers: A Story of Success, Little, Brown and Company: New York.

Green, Melanie C. and Timothy C. Brock (2000), "The Role of Transportation in the Persuasiveness of Public Narratives," Journal of Personality and Social Psychology, 79(5), 701-721.

Gregan-Paxton, Jennifer and Deborah Roedder John (1997), “Consumer Learning by Analogy: A Model of Internal Knowledge Transfer," Journal of Consumer Research, (December), 266-284.

Hayes, Andrew F. (2014). Introduction to Mediation, Moderation, and Conditional Process Analysis. New York: The Guilford Press.

Heisley, Deborah D. and Sidney J. Levy (1991), “Autodriving: A Photoelicitation Technique,” Journal of Consumer Research, 18(3), 257-272.

Hoegg, Joandrea and Joseph W. Alba (2007), “Taste Perception: More than Meets the Tongue," Journal of Consumer Research, 33(March), 490-498.

Holbrook, Morris B., and William L. Moore (1981), "Feature Interactions in Consumer Judgments of Verbal versus Pictorial Presentations," Journal of Consumer Research, 8 (1), 103- 13 .

Hughson, Angus L. and Robert A. Boakes (2001), “The Knowing Nose: The Role of Knowledge in Wine Expertise," Food Quality and Preference, 13(October-December), 463-472.

Klein, Gary (1998), Sources of Power: How People Make Decisions, Cambridge: MIT Press. LaTour, Kathryn A., and Michael S. LaTour, (2010), “Bridging Aficionados' Perceptual and 
Conceptual Knowledge to Enhance how they Learn from Experience," Journal of Consumer Research, 37 (4), 688-697.

Luchins, Abraham S. (1942). "Mechanization in Problem Solving: The Effect of Einstellung". Psychological Monographs, 54 (6): i-95.

Maciel, Andre F. and Melanie Wallendorf (2017), “Taste Engineering: An Extended Consumer Model of Cultural Competence Constitution," Journal of Consumer Research, 43(February). 726-746,

MacInnis Deborah J. and Linda L. Price (1987), “The Role of Imagery in Information Processing: Review and Extensions," Journal of Consumer Research, 13(March), 473491.

Melcher, Joseph M. and Jonathon W. Schooler (1996), “The Misrememberance of Wines Past: Verbal and Perceptual Expertise Mediate Verbal Overshadowing Effects," Journal of Memory and Language, 35 (April), 231-45.

Monga, Alokparna Basu and Deborah Roedder John (2007), “Cultural Differences in Brand Extension Evaluation: The Influence of Analytic versus Holistic Thinking," Journal of Consumer Research, 33(March), 529-536.

Nisbett, Richard E., Kaiping Peng, Incheol Choi, and Ara Norenzayan (2001), "Culture and Systems of Thought: Holistic versus Analytic Cognition," Psychological Review, 108 (April), 291-310.

Noble, Ann C., Rich A. Arnold, John Buechsenstein, E. Jane Leach, Janice O. Schmidy, and Peter M. Stern (1987), "Modification of a Standardized System of Wine Aroma Terminology," American Journal of Enology and Viticulture, 38 (2), 143-46.

Richler, Jennifer J. Thomas Palmeri and Isabel Gauthier (2012), "Meanings, Mechanisms and 
Measures of Holistic Processing,” Frontiers in Psychology, 3(December), 1-6.

Ruskin, John (1991, 1857). The Elements of Drawing. London: The Herbert Press.

Schott, GD (2011),'Doodling and the Default Network of the Brain," The Lancet, 378 (9797) (September) 1133-1134.

Spiggle, Susan (1994), "Analysis and Interpretation of Qualitative Data in Consumer Research," Journal of Consumer Research, 21 (December), 491-503.

Thompson, Craig J. (1997), “Interpreting Consumers: A Hermeneutical Framework for Deriving Marketing Insights from the Texts of Consumers' Consumption Stories,” Journal of Marketing Research, 34 (November), 438-55.

Thompson, Edmund (2007), "Development and Validation of an Internationally Reliable Short Form of the Positive and Negative Affect Schedule," Journal of Cross-Cultural Psychology, 38(2), 227-42.

Townsend, Claudia and Barbara E. Kahn (2014), “The 'Visual Preference Heuristic': The Influence of Visual versus Verbal Depiction on Assortment Processing, Perceived Variety, and Choice Overload," Journal of Consumer Research, 40 (February), 9931015.

Tversky, Barbara (2011) “Obsessed by Lines,” in Kantrowitz, Brew \& Fava (eds). Proceedings of Thinking through Drawing: Practice into knowledge. New York: Teachers College, Columbia University, Art and Art Education Program, 15-18.

Wang, Jin, and Bobby Calder (2006), “Media Transportation and Advertising," Journal of Consumer Research, 33 (2), 151-162.

Wells, William D. (1993), “Discovery-oriented Consumer Research,” Journal of Consumer Research, 19 (4), 489-504. 
West, Patricia M., Christina L. Brown and Stephen J. Hoch (1996), “Consumption Vocabulary and Preference Formation,” Journal of Consumer Research, 23 (September), 120-135.

Wilson, Timothy D. and Jonathan W. Schooler (1991), “Thinking Too Much: Introspection Can Reduce the Quality of Preferences and Decisions," Journal of Personality and Social Psychology, 60 (2), 181-92.

Wood, Stacy L. and John G. Lynch, Jr. (2002), "Prior Knowledge and Complacency in New Product Learning," Journal of Consumer Research, 29(December), 416-426.

Yingling, Robert W. (1962), "Classification of Reaction Patterns in Listening to Music," Journal of Research in Music Education, 10(2), 105-120.

Zaltman, Gerald (1997), “Rethinking Market Research: Putting People Back In,” Journal of Marketing Research, 34 (November), 424-37. 
Table 1.Participant Information

\begin{tabular}{|l|l|l|}
\hline Participant & Age & Wine Related Experience \\
\hline Theo & 56 & Sales and marketing; Wine educator; Beverage director \\
\hline Jason & 42 & Wine director; Vineyard sommelier \\
\hline Maggie & 48 & Wine retail director; Chef; Wine judge; Educator \\
\hline Young & 48 & Beverage director; Award winning sommelier \\
\hline Yang & 38 & Wine retail owner; Head sommelier; Educator \\
\hline James & 65 & VP of wine distribution company; Wine judge \\
\hline Doug & 51 & Educator; Journalist; Wine judge; Speaker. \\
\hline Ted & 61 & Educator; Writer; Consultant; Wine retail sales \\
\hline Ronald & 32 & Educator; Sommelier at Michelin restaurant \\
\hline Kris & 34 & $\begin{array}{l}\text { Corporate beverage director at major hospitality group; Sommelier at Michelin star } \\
\text { restaurants }\end{array}$ \\
\hline
\end{tabular}




\section{FIGURE 1: TASTING GRID}

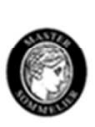

Certified Sommelier Tasting Exam

Red Wine Tasting Grid

Name

Fill in the correct lettered space completely

AROMA / FLAVOR ASSESSMENT

1 Fruit Generic Descriptor:

a) Black Fruit b) Red Fruit c) Blue Fruit d) Othet

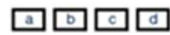

2 List Speciffic Descriptor(s):

3. Non-truit Generic Descriptor:

4 List Spsecific Descriptor(s):

5. EarthMineral Generic Descriptor:

a) Floral b) Spice c) Herbs of Other

ㅁㅁㅁㅁ

6. List Specific EarthMineral Descriptor(s):

7 Use of Oak:

a) LittleNo Earth b) Stones Minerals c)Leaves d) Mushrooms $a \square \square \square$

8. List Specific Wood Descriptor(s):

a) Little No Oak b) Aged in Oak

$a$

STRUCTURE ASSESSMENT

9. Sugar

10. Acid

a) Low b) Med c) High

a) Low b) Med c) High

a) Low b) Med c) High

a) Low b) Med c) High

a) Gamay b) Cabernet SauvignonMerlot c) Pinot Noir

12. Tannin

a) Short b) Med e) Long

ab

13 Finish

a) Cool b) Moderate c) Warm

INITIAL AND FINAL CONCLUSIO

14. Climate:

a) Old World b) New World

d) Syrah/Shiraz e) Sangiovese if Zintandel

a) France b) italy e) United States d) Australis

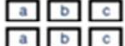

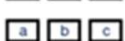

17. Country:

e) Spain if New Zealand

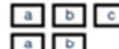

붑ㅁㅁㅁ

18. Vintage:

$\begin{array}{llll}\text { a) } 1995-1999 & \text { b) 2000-2002 } & \text { c) 2003-2005 }\end{array}$

ㅁㅁㅁㅁ

마 
FIGURE 2: MEMORY ACCURACY BY MODALITY AND COMPOSITIONAL APPROACH

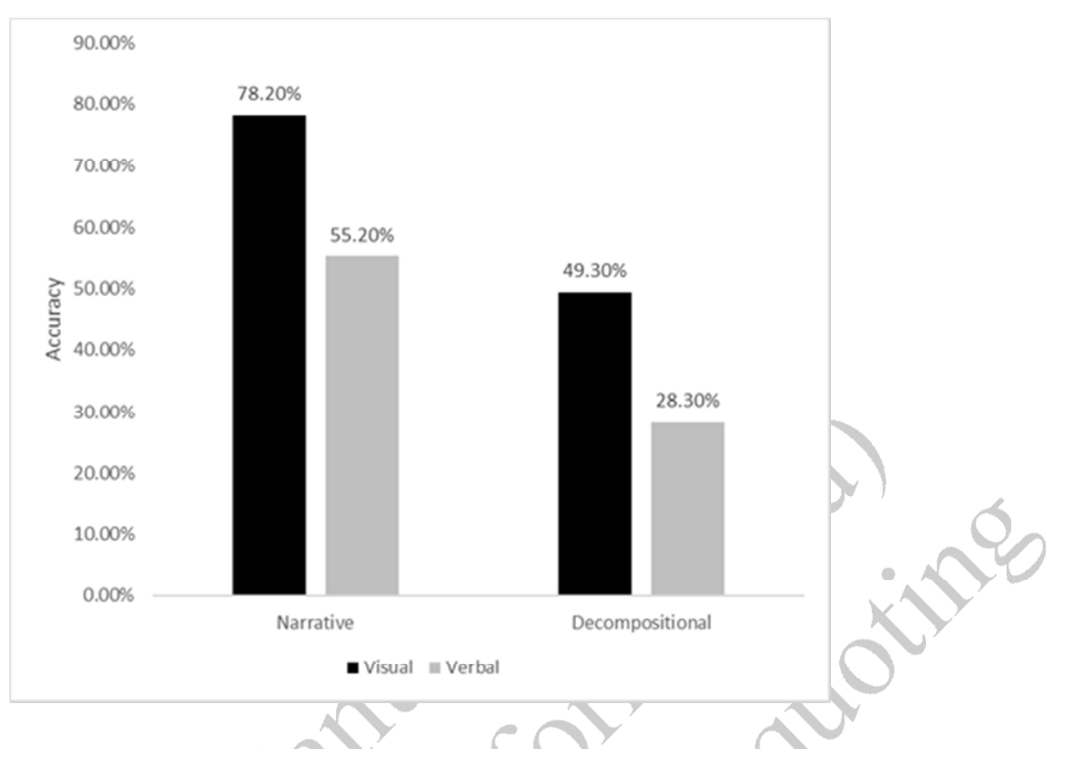


FIGURE 3: MEMORY ACCURACY BY EXPERIENCE

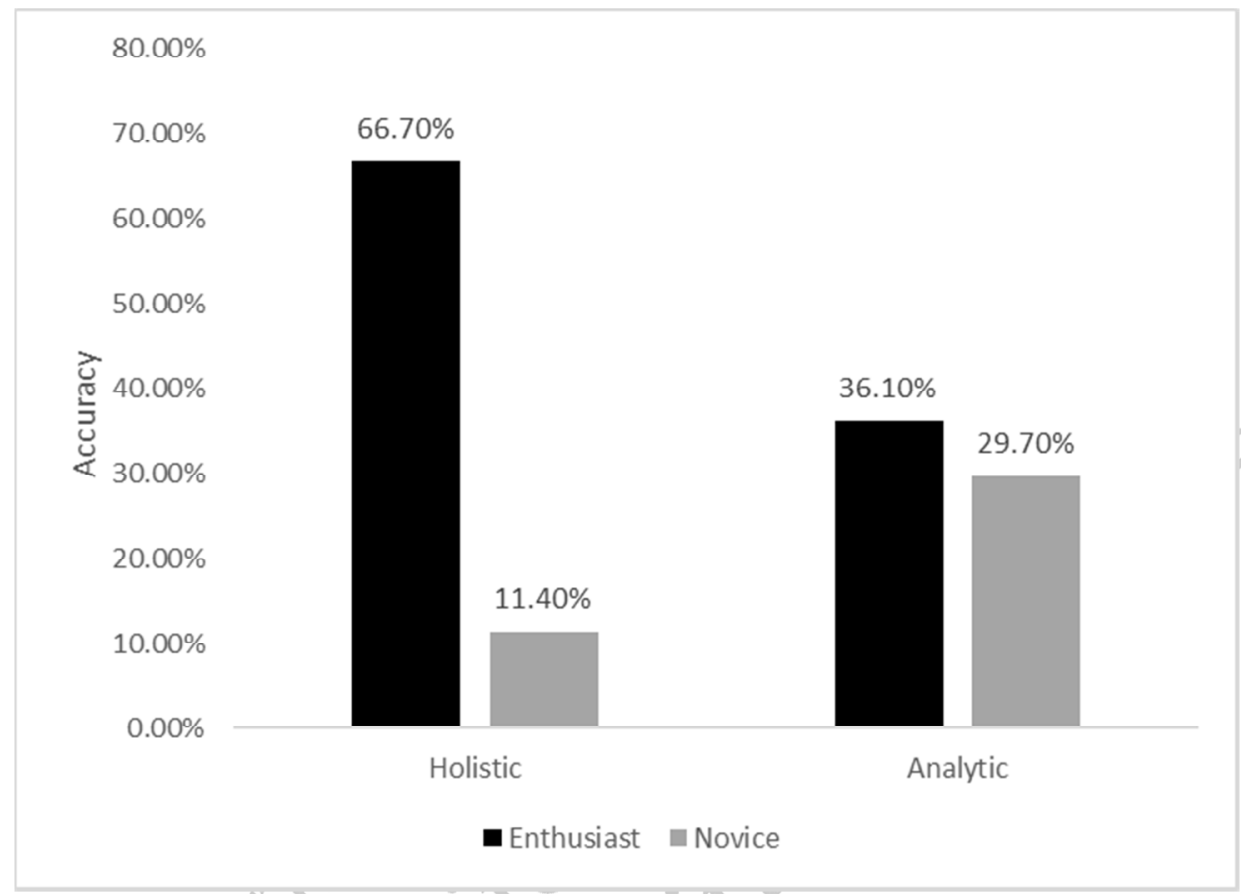


FIGURE 4: DIFFERENTATION BY EXPERTISE AND LEARNING APPROACH

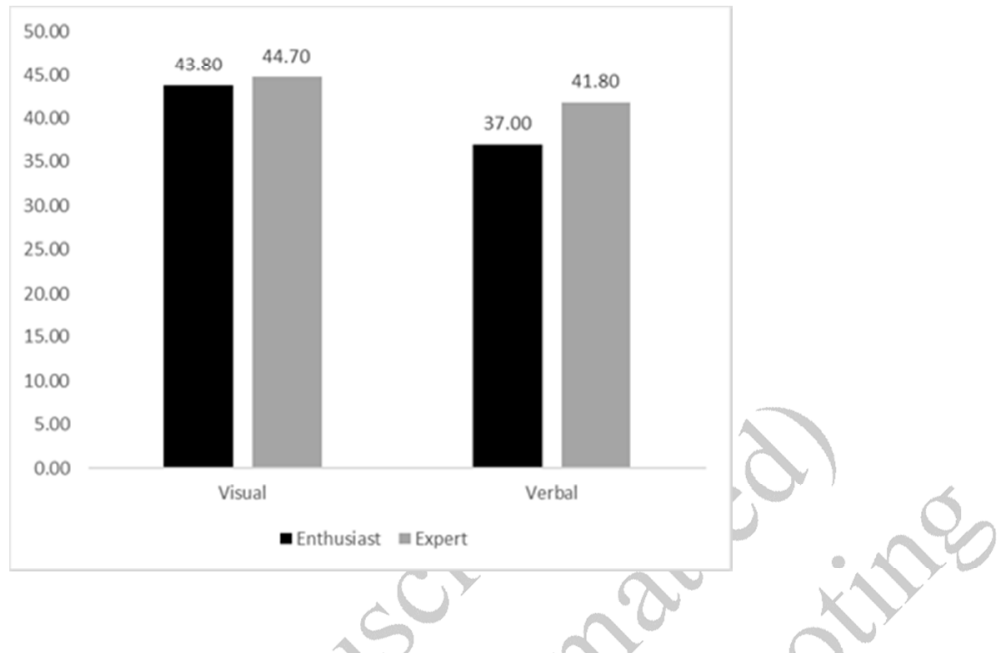


FIGURE 5: STAGES OF LEARNING

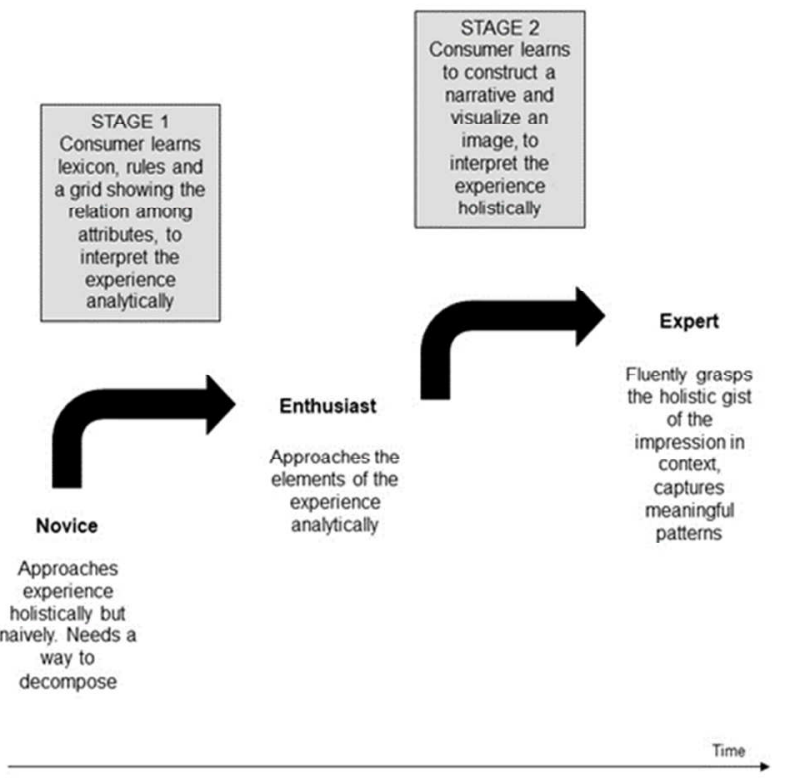




\section{HEADINGS LIST}

1) CONCEPTUALIZATION

2) Stages in Development of Expertise

2) Development of Hedonic Expertise is Stage-Gated

1) HYPOTHESES

2) What is Holistic Processing?

2) Developing Expertise with the Enthusiast

1) STUDY 1: EXPLORATORY DISCUSSIONS WITH MASTER SOMMELIERS

2) Method

2) Analysis

2) Results

3) Stage One: Obtaining Declarative Knowledge.

3) Stage Two: Tuning Toward Perceptual Experience.

2) Discussion

1) OVERVIEW OF THE EXPERIMENTAL STUDIES

1) STUDY 2: DEFINING HOLISIC PROCESSING IN TASTE: ROLE OF MODALITY AND NARRATIVE

2) Method

3) Sample.

3) Procedure.

2) Results

3) Manipulation Check.

3) Memory Performance.

2) Discussion

1) STUDY 3: TRANSPORTING INTO TASTE

2) Method

3) Sample.

3) Procedure. 
2) Results

3) Transportation.

3) Memory Performance.

3) Mediation Analysis.

2) Discussion

1) STUDY 4: STAGE-GATED TASTE LEARNING

2) Method

3) Sample.

3) Procedure.

2) Results

3) Manipulation Check.

3) Memory Performance.

2) Discussion

1) STUDY 5: ENTHUSIASTS APPROACH EXPERTISE

2) Method

3) Sample.

3) Procedure.

2) Results

3) Perceptual Differentiation

2) Discussion

1) GENERAL DISCUSSION

2) A New Lens on Consumer Learning and Expertise

2) Limitations

1) DATA COLLECTION INFORMATION

1) APPENDIX A: INSTRUCTIONS FOR STUDY 2

1) APPENDIX B: SAMPLE SHAPE DRAWING

1) REFERENCES 